\title{
Sociolingüística del poder en el Siglo de Oro. De reverencias, altezas, mercedes, señorías y otras formas de tratamiento en el teatro de Calderón de la Barca ${ }^{\top}$
}

Sociolinguistics of power in the Spanish Golden Age. Of reverences, highnesses, mercies, lordships and other forms of treatment in the theatre of Calderón de la Barca

\section{Carmela Pérez-Salazar}

Universidad de Navarra, GRISO

ESPAÑA

cpsalazar@unav.es

[Hipogrifo, (issn: 2328-1308), Volumen extraordinario, 1, 2018, pp. 97-119]

Recibido: 01-08-2017 / Aceptado: 30-10-2017

DOI: http://dx.doi.org/10.13035/H.2018.extra01.08

Resumen. Este trabajo revisa los recursos que se emplean en obras dramáticas de Calderón de la Barca para el tratamiento a los representantes de la autoridad; esto es, se analiza la presencia en escena de los que Gonzalo Correas denomina «nombres de honor», para los que el protocolo de los siglos XVI y XVII impone pautas muy rigurosas. El estudio se basa en una selección de obras en las que participan representantes del poder político, militar y eclesiástico, y personajes de distinto rango, sexo y edad.

1. Este trabajo se enmarca en el proyecto FFI2014-52007-P, «Autoridad y poder en el teatro del Siglo de Oro. Estrategias, géneros, imágenes en la primera globalización», Ministerio de Economía y Competitividad, Gobierno de España. Dirección General de Investigación Científica y Técnica. Programa Estatal de Fomento de la Investigación Científica y Técnica de Excelencia. 
Palabras clave. Formas y fórmulas de tratamiento; teatro Siglo de Oro; sociolingüística histórica.

Abstract. This work reviews the resources that are used in dramatic works of Calderón de la Barca for the treatment of the representatives of the authority; that is, the presence on stage of what Gonzalo Correas calls «names of honor», for which the protocol of the sixteenth and seventeenth centuries imposes very strict guidelines, is analyzed. The study is based on a selection of works in which representatives of political, military and ecclesiastical power, and characters of different rank, sex and age participate.

Keywords. Forms and Treatment Formulas; Spanish Golden Age Theatre; Historical Sociolinguistics.

\section{INTRODUCCIÓN}

Si hay una cuestión lingüística inseparable de la perspectiva social es la de las formas de tratamiento. El conjunto de normas mantenidas en el trato social -así se ha definido la cortesía (DUE, s.v.) - incluye pautas verbales, y las formas de tratamiento no son sino la codificación lingüística de las normas sociales. Quizá sea esa vinculación, que permite indagar, desde la expresión lingüística, aspectos de la organización social y de las relaciones de poder y solidaridad², la que ha despertado el interés de tantos investigadores.

En lo que respecta al Siglo de Oro, existen numerosos trabajos sobre los elementos que codifican la relación social entre hablante y destinatario, lo que puede llevar a pensar en un espacio ya agotado ${ }^{3}$. Sin embargo, la complejidad social en la España de los siglos XVI y XVII y las transformaciones lingüísticas que suceden en español clásico, y, además, la riqueza de la producción escrita de este tiempo, dejan abiertas las posibilidades de investigación. Me permito recordar el hecho de que durante este período se producen cambios importantes hacia la consolidación del sistema moderno de formas de tratamiento (con sus numerosas variantes), y se fijan los usos de las fórmulas que incluyen los apelativos honoríficos señoría, excelencia, alteza, majestad, paternidad, reverencia, entre otros ${ }^{4}$.

2. Ver Brown y Gilman, 1960, pp. 255-261, sobre el significado de los conceptos de poder y solidaridad, Respecto de la incorporación de estos conceptos al estudio sociolingüístico remito a Moreno Fernández, 2015, pp. 149-154.

3. En la imposibilidad de ofrecer aquí una relación de todo lo escrito al respecto, me permito recordar las aportaciones de del Barrio (1997), Ly (1981), Enguita (1986), Martínez Gavilán (1988), Moreno (2002), Medina (2002) y Pérez-Salazar (2002), que analizan las formas y fórmulas de tratamiento en corpus literarios (fundamentalmente) y no literarios. Engelbert (1973), Carrasco (1983) y Torres (1989) dedican sus trabajos precisamente a Calderón de la Barca. Son imprescindibles Lapesa, 2000 [1970] (en adelante Lapesa 2000), sobre la evolución de las formas y fórmulas de tratamiento, y Fontanella (1999), para una revisión de los sistemas pronominales de tratamiento en el mundo hispánico.

4. Alvar y Pottier, 1987, pp. 130-133; Lapesa, 2000, pp. 316-325. 
El propósito de estas páginas es revisar y analizar los recursos nominales y pronominales que se emplean, en obras dramáticas de Calderón de la Barca, para el tratamiento a la autoridad; me ocuparé, en concreto, de los denominados por Correas «títulos y nombres de honor» (Arte, p. 213) y de las formas de tratamiento que los acompañan, para los que el protocolo de los siglos XVI y XVII impone pautas muy rigurosas. Obligada por la necesaria limitación que impone una aportación de estas características, he seleccionado un grupo de obras pertenecientes a distintos subgéneros, en las que participan representantes de la autoridad (política, militar y eclesiástica) y personajes de distinto rango, sexo y edad, involucrados en situaciones vitales dispares. Las obras analizadas son las que siguen ${ }^{5}$ :

Amor, honor y poder

El alcaide de símismo

La cisma de Ingalaterra

El príncipe constante

La dama duende

La vida es sueño

El alcalde de Zalamea

El conde Lucanor

El santo rey Don Fernando. Segunda parte

Asimismo, he incluido en el análisis los entremeses editados por Ma Luisa Lobato en su obra Teatro cómico breve.

La elección del género dramático y del autor no es casual. La variedad de interacciones que se producen en las obras teatrales las hace especialmente idóneas para el análisis de una cuestión que necesita la perspectiva pragmática: el teatro ofrece intercambios casi siempre dialógicos, y recrea multitud de situaciones de interlocución oral, corteses y no corteses ${ }^{6}$. En cuanto a Calderón -si fuera necesario justificar la conveniencia de indagar en su producción dramática- cabe destacar la amplitud cronológica que recorre su obra, que permite abarcar seis décadas del siglo XVII y alcanzar hasta el último tercio de la centuria ${ }^{7}$. Valga añadir que estudios previos sobre el uso de los tratamientos en Calderón señalan que el sistema

5. Las ordeno cronológicamente según criterio de Cruickshank, 2011, pp. 500-508, y de los editores de las obras. En el apartado Bibliografía de este trabajo se indican las ediciones manejadas. Remito, además, a Arellano, 1995, pp. 450-523, para la periodización y la revisión crítica de los géneros en la obra dramática de Calderón

6. Haverkate, 1994, pp. 77-79, distingue entre actos de habla corteses (que incluyen los actos expresivos, indicadores de agradecimiento, felicitación, pésame, disculpa, cumplido, saludo, y los actos comisivos, indicadores de promesa e invitación) y actos no corteses (que incluyen los denominados actos asertivos y exhortativos); según indica, los actos no corteses pueden ser, asimismo, descorteses (insultos o agravios) o no descorteses. Para una explicación de las concepciones modernas de la cortesía y su conexión con las formas de tratamiento, ver Blas Arroyo, 1994, pp. 12-23.

7. De este modo, se puede incorporar aquí al menos una parte de ese tercer «subperíodo» que establece Girón, 2004, p. 885, en español clásico, de acuerdo con la evolución interna del idioma y con las circunstancias políticas, las ideas lingüísticas y la literatura, y que comprende desde 1648 hasta 1726: «desde los últimos años del reinado de Felipe IV al primer Borbón, desde el P. Villar a la Real Academia Española, desde Calderón y los epígonos de la literatura barroca a Feijoo». 
de interlocución que emplea en sus obras dramáticas difiere, más que el de otros autores clásicos, de la norma vigente en su épocå ${ }^{8}$.

\section{FORMAS DE TRATAMIENTO EN GRAMÁTICAS Y TRATADOS DEL SIGLO DE ORO. TÍTU- LOS Y NOMBRES DE HONOR}

Me permito recordar, como marco previo al análisis de las obras, que las posibilidades de dirigirse a un interlocutor en español clásico incluyen tres elementos pronominales: tú, vos (que en el siglo XVII se estima en decadencia) y él, además de merced, generalizado desde el siglo XV en la fórmula respetuosa vuestra merced (de la que parten las variantes vuessa merced, vuessarced, vuessansted, vuesasted, vuessasté, así como las consideradas vulgares voarced, voacé, vucé, vuested, vosted, vusted, usted ${ }^{9}$, y varias fórmulas expresivas de reverencia compuestas de un posesivo más un sustantivo abstracto.

Una de las muestras de la preocupación sociolingüística que existe en el Siglo de Oro son las abundantes noticias que dejan gramáticos y tratadistas -observadores excepcionales del uso y conocedores del valor preciso de los tratamientos y títulos - sobre las normas y la práctica de su tiempo ${ }^{10}$. Además de presentar los elementos que conforman el sistema, sus indicaciones apuntan a las características de los participantes en la interlocución (edad, formación y procedencia rural o urbana del hablante; rango y estamento del destinatario) y a las circunstancias en las que sucede el intercambio (intención del hablante, gravedad o familiaridad de la situación comunicativa), y anuncian incluso cambios sociales que estaban sucediendo en este tiempo. En el complejo entramado de recursos que presentan, incluyen las formas específicas -o exclusivas- que se destinan a representantes de la nobleza y del poder político, eclesiástico y militar.

Son conocidas las palabras de Juan de Luna en sus Diálogos familiares ${ }^{11}$, que, en los albores del siglo XVII, expone con sumo rigor la organización jerárquica (de abajo arriba) de las formas de tratamiento (con referencias incluso a variantes formales) ${ }^{12}$ :

El primero y mas vaxo es tu, que se da a los niños, o a las personas que queremos mostrar grande familiaridad o amor. Vos se dize a los criados o vasallos.

8. Torres, 1989, p. 319

9. Lapesa 2000, pp. 319-320. Pla Cárceles (1923), que estudia la evolución de vuestra merced, considera que la forma usted debía de ser usual hacia 1670. Sáez Rivera (2006) aporta nuevos datos sobre el proceso de gramaticalización del sintagma en pronombre.

10. Estos y otros testimonios en Lapesa (2000) y Alvar y Pottier (1987).

11. Consultado a través del CORDE. También en Lapesa, 2000, p. 319, nota 23.

12. Existía, asimismo, la posibilidad de recurrir a fórmulas intermedias, a las que se refiere Lucas Gracián (1593, pp. 34-35): «Van algunos assimesmo tan llenos de cuidados en estas cerimonias, que hallan medio de nombrar entre el tú y vos y él y V.m., haziendo seis grados de cortesía, que ninguna nación alcançó tantos, porque si miramos al francés, con solo el vos sustenta todos grados». Enguita, 1983, pp. 298-299, incluye las apreciaciones de Baltasar Gracián sobre las fórmulas de interlocución a mediados del siglo XVII 
Vuesaste, vuesa merced, vuestra merced, que significan una mesma cosa, y no se muda segun la calidad de las personas (segun algunos piensan), pero esta mudança viene de parte del que habla, que si es de los mas ladinos dize vuesaste, el comun vuesa merced, y los mas rústicos vuestra merced. El qual título se da a todos, grandes y pequeños. Vuestra Señoria, a los condes, marqueses, y obispos, a los quales se deue de derecho. A los varones, vizcondes, abades de mitra, sus amigos solo les dan el titulo de Señoria. A los presidentes y oidores, le llaman Señoria solo en sus tribunales. Vuesa excelencia, a los duques, virreyes y generales de armadas. Vuesa Alteça, a los hermanos del rey, o a los príncipes soberanos. A los reyes, Vuesa Magestad. A los Eclesiasticos se dize Vuesa merced, como al comun de los legos. A los frayles, Vuesa Reverencia. A los prelados de un monasterio, Vuesa Paternidad. A los de una Prouincia, Vuesa Reverenda Paternidad. A los generales de una religion, Vuesa Paternidad Reuerendissima. A los arçobispos y cardinales, Vuesa illustrissima Señoria. Al Papa, Vuesa Santidad.

En la misma centuria, Gonzalo Correas (Arte, p. 363) detalla el empleo de los cuatro elementos básicos según las «calidades» de las personas. El desorden de los que el autor denomina «otros títulos y nombres de honor», que también explica (Arte, p. 213), y la inflación de recursos hicieron necesaria -informa Correas - la publicación de una Premática13:

Devese tanbien mucho notar la desorden, i discordante concordia, que á introduzido el uso, ora por modestia, ora por onrra, ó adulazion. Para lo qual es menester primero advertir que se usan quatro diferenzias de hablar para quatro calidades de personas, que son: vuestra merzed, él, vos, tu [...]

De merzed usamos llamar à las personas à quien rrespetamos, i debemos ò queremos dar onrra, como son: xuezes, cavalleros, eclesiasticos, damas, i xente de capa negra, i es lo mas despues de señoria.

Él usan los maiores con el que no quieren darle merzed, ni tratarle de vos, que es mas baxo, i propio de amos á criados, i la xente vulgar i de aldea, que no tiene uso de hablar con merzed, llama de él al que quiere onrrar de los de su xaez.

De vos tratamos à los criados i mozos grandes, i à los labradores, i à personas semexantes; i entre amigos adonde no ai gravedad, ni cunplimiento se tratan de vos, i ansi en rrazonamientos delante de rreies i dirixidos á ellos se habla de vos con devido rrespeto i uso antiguo.

De tu se trata á los muchachos i menores de la familia, i á los que se quisieren bien: i quando nos enoxamos i rreñimos con alguno le tratamos de él, i de vos por desden.

Tanbien ai otros titulos i nonbres de onor con que hablamos à las personas i las hablamos sin el nonbre propio: à los Rreies dezimos Magestad; à los prinçipes Alteza; à los grandes Eszelencia; à otros titulados i obispos Señoria; à todos los otros Merzed [...] A los rreligiosos provinziales llaman Paternidad Rreverendísima; à los perlados, Paternidad; a los demás, Reverenzia, como digo. Solíase usar sin

13. Es la Premática publicada en 1557 por Felipe II, y después por Felipe III y Felipe IV, «En que se da la orden que se ha de tener y guardar en los tratamientos y cortesías de palabra y por escrito». Disponible en play.google.com./books. En el apartado Bibliografía de este trabajo aparece como Leyes. 
orden de otras adulaziones i encarezimientos: Magnífico, Illustre, Ilustrísimo; ia se quitó tal abuso por prematica rreal, i se rreservó para los señores i prelados.

Al referirse a los que llama «títulos mayores», Lucas Gracián ${ }^{14}$ aportaba, algunos años antes, un valioso testimonio sobre algunas costumbres -el desorden que denuncia Correas - indicadoras de cambios sociales ${ }^{15}$.

Y no quiero tratar de lo que se puede dezir desde el $\mathrm{V}$. $\mathrm{m}$. arriba, ni en los títulos mayores, porque sería meternos en un gran laberintio. Baste que han dado tal baxa con el tiempo, que se han levantado la comunidad de gente ordinaria con los títulos de Illustres, con tanta fuerça y conjuración, que los pobres Nobles, y muy Nobles, Magníficos y muy Magníficos, que solían usar, andar ya huidos y desterrados de su antigua patria y nación. Y assí viendo esto la nobleza de cavalleros y gente calificada, se han aprovechado de subirse un grado o dos más arriba, para poderse diferenciar, especialmente en las cartas, de esta generación robadora de sus illustres títulos.

\section{EL TRATAMIENTO A LA AUTORIDAD EN LAS OBRAS DE CALDERÓN DE LA BARCA}

La consulta del CORDE y la lectura de las obras seleccionadas permite afirmar, en primer lugar, que el número de nombres honoríficos aplicados a los representantes de la autoridad se simplifica notablemente en escena en comparación con el protocolo expuesto, complejo y riguroso, vigente en el siglo XVII. Los personajes de Calderón se sirven de un sistema de reverencia relativamente sencillo, que se reduce a unos pocos apelativos - compatibles con vos o con tú según la distancia o la proximidad vivencial entre los interlocutores y según la formalidad que impone el intercambio verbal-y de algunos elementos de presencia excepcional ${ }^{16}$.

Cabe señalar la ausencia de apelativos específicos para los representantes de la jerarquía eclesiástica: Paternidad y Reverencia o Reverendo y Reverendísimo ${ }^{17}$, que sí se encuentran, en cambio, en el teatro de Lope $^{18}$, pese a que en algunas obras de las aquí analizadas participan miembros de la autoridad de la Iglesia, en actos verbales corteses y no corteses. Así, don Ramón, Obispo de Segovia, y don Arias, arzobispo de Santiago, reciben del Rey Fernando un vos respetuoso, como

14. Gracián, El Galateo español, pp. 34-35.

15. También Baltasar Gracián señala esta circunstancia, indica Enguita, 1986, p. 299: «el autor del Criticón se hace eco del desmedido afán de sus contemporáneos por ascender en el tratamiento, y, por consiguiente, en la estimación social».

16. Indicaré, tras cada cita, el número de versos y la página si la edición manejada es edición crítica, y únicamente las páginas si no lo es.

17. En el siglo XVII Paternidad es habitual especialmente en la prosa cronística y religiosa y en las relaciones epistolares, según se aprecia en el CORDE, al igual que Reverendo y Reverendísimo, con o sin Paternidad, Padre, Maestro, Señor, Obispo... El tratamiento Reverencia, según Covarrubias, se debe a los sacerdotes y religiosos; Reverendísimo es título de prelado (Cov., s.v. reverencia).

18. Ly, 1981, p. 245, recoge vuesa reverencia y su caridad. En p. 176 presenta una relación de todos los tratamientos hallados en las obras de Lope de Vega. 
otras «personas de gran dignidad» ${ }^{19}$ a las que se dirige el rey al pronunciar la arenga antes de tomar las armas: «vos, don Arias, arzobispo de Santiago» (El santo rey don Fernando, vv. 422-423; pp. 93-9420). En circunstancias comunicativas de confianza, rey y obispo se tratan de tú, pero difieren notablemente los vocativos que intercambian (El santo rey don Fernando, vv. 662-722; pp. 106-108). Así pues, si el tratamiento pronominal es recíproco, no lo es el nominal:

\begin{tabular}{ll} 
SEGOVIA & \multicolumn{1}{c}{ Señor, } \\
& manda que a favorecer \\
& a Alfonso vayan [...] \\
REY & ¡Ay, Ramón, que estos favores \\
& de superior mano vienen!
\end{tabular}

Tratamiento de vos, igualmente sin sustantivo o adjetivo honorífico, recibe, en La cisma de Ingalaterra, por parte de la reina Catalina, el cardenal Volseo, que aparece caracterizado como persona que encarna los peores defectos (lisonjero, soberbio, arrogante, necio...). Por este motivo, no abundan en la obra los intercambios corteses con el cardenal27; de hecho, la reina Catalina le dispensa, mediante el vos (aquí en la forma pronominal átona), el respeto que corresponde a su rango, pero no duda en manifestar verbalmente su desprecio 22 :

$\begin{array}{ll}\text { CATALINA } & \text { ¡Loco, necio, vano! } \\ & \text { Por Príncipe soberano } \\ & \text { de la Iglesia hoy os respeto; } \\ & \text { aquesa púrpura santa } \\ & \text { que, por falso y lisonjero, } \\ & \text { de hijo de un carnicero } \\ & \text { a los Cielos os levanta. }\end{array}$

Según las exigencias del protocolo, excelencia se destina solo a los grandes, a duques, virreyes y generales. Vuexcelencia es la forma escogida por Calderón para acrecentar la confusión acerca de la identidad de la protagonista de La dama duende: doña Ángela oculta su identidad a don Manuel, pero el tratamiento que le otorga Beatriz resulta inequívoco, y así lo interpreta don Manuel (La dama duende, vv. 2408-2422; pp. 107-108)23:

19. El primer diccionario académico indica todavía que vos se emplea «hablando con personas de gran dignidad» (Aut., s.v.).

20. Para el tratamiento que dispensa el rey a distintos representantes de la autoridad, ver pp. 82-94. A lo largo de la obra se observa el tuteo habitual entre el rey Fernando y los obispos; solo el rey cambia al vos ocasionalmente.

21. Según indica el editor, que destaca la vanidad insaciable del cardenal, Calderón es escrupoloso con la figura histórica, pero el personaje adquiere más protagonismo en la obra que en la fuente histórica ( $L a$ cisma de Ingalaterra, p. 42).

22. La cisma de Ingalaterra, vv. 660-666; p. 152.

23. El mismo don Manuel atribuye el tratamiento de excelencia a un noble (La dama duende, vv. 24882493; p. 111): «venme aquí a mí en una casa/ que dueño tan noble tiene/ - de Excelencia por lo menos -/ lleno de asombros crueles/ y tan lejos de la mía». 


\begin{tabular}{|c|c|}
\hline DOÑA BEATRIZ & $\begin{array}{l}\text { Ya el agua y dulce está aquí. } \\
\text { Vuexcelencia mire si... } \\
{[\ldots]}\end{array}$ \\
\hline ÑA ÁNGELA & $\begin{array}{l}\text { ¡Qué error, y qué impertinencia } \\
\text { Necia, ¿quién es "Excelencia"? } \\
\text { ¿Quieres engañar así } \\
\text { al señor Don Manuel, } \\
\text { para que con eso crea } \\
\text { que yo gran señora sea? }\end{array}$ \\
\hline DÑA BEATRIZ & Advierte... \\
\hline N MANUEL & $\begin{array}{l}\quad \text { (De mi cruel } \\
\text { duda salí con aquel } \\
\text { descuido: agora he creído } \\
\text { que una gran señora ha sido } \\
\text { que por serlo se encubrió, } \\
\text { y que con el oro vio } \\
\text { su secreto conseguido). }\end{array}$ \\
\hline
\end{tabular}

El mismo tratamiento emplea Juan Crespo para dirigirse al general don Lope en El alcalde de Zalamea (vv. 322-330; p. 301). Obsérvese igualmente el voseo cortés (en la forma verbal fuérades) que le dispensa el capitán:

\begin{tabular}{ll} 
LOPE & \multicolumn{1}{c}{ Mal } \\
& $\begin{array}{l}\text { los trabajos de la guerra, } \\
\text { sin aquesta libertad } \\
\text { se llevaran; que es estrecha } \\
\text { religión la de un soldado, } \\
\text { y darle ensanchas es fuerza. }\end{array}$ \\
JUAN & Con todo eso es linda vida. \\
LOPE & ¿Fuérades con gusto a ella? \\
JUAN & Sí, señor, como llevara \\
& por amparo a Vuexcelencia.
\end{tabular}

Resulta llamativa la ausencia del sustantivo señoría - presente, en cambio, en el teatro de Lope en el trato de inferior a superior ${ }^{24}$ - en las obras de Calderón, posiblemente el título más complejo en esta época desde el punto de vista social, por la diversidad de dignidades a las que podía atribuirse: según se aprecia en las palabras de Juan de Luna y en las numerosas indicaciones que le dedica la Premática real ${ }^{25}$, se aplicaba a los representantes más altos de la jerarquía eclesiástica y de la nobleza, y a embajadores, esposas de los Grandes, damas y dueñas de honor

24. Ver Ly, 1981, p. 219. También se encuentra en el Quijote (Del Barrio, 1997, pp. 362-363), además de vuestra excelencia y vuestra grandeza.

25. Leyes, títulos 10 a 16.

HIPOGRIFO, Volumen extraordinario, 1, 2018 (pp. 97-119) 
de la reina, entre otros. Tan solo una forma de empleo excepcional en la época ${ }^{26}$, vuseñoría, aparece en boca de un personaje de entremés, Franchota-Entremés de La Franchota- que se dirige al alcalde ${ }^{27}$; la elección de un elemento exclusivo de las clases superiores y que resulta excesivo para el interlocutor, junto con la mezcla de códigos que emplea el personaje, contribuye a construir la comicidad ${ }^{28}$ :

FRANCHOTA Si vole vuseñoría cualque altra cousa de la vita mía, diga cualque parola.

Al embajador de Francia, Carlos, le dirige Tomás Boleno, viejo y noble, el vocativo adaptado al español que corresponde a su rango y a su origen, monsiur, unido a un vos respetuoso (el tratamiento es mutuo), en un acto verbal de súplica en el que se acumulan los recursos corteses ${ }^{29}$. El testimonio es único en el teatro de Calderón, pero no en su tiempo ${ }^{30}$ :

\begin{tabular}{ll} 
TOMÁs & $\begin{array}{l}\text { Y pues hablar es forzoso } \\
\text { de otra cosa, suplicaros } \\
\text { quiero, monsiur, y rogaros, } \\
\text { como a francés generoso } \\
\text { me honréis con vuestra persona } \\
\text { esta tarde [...] }\end{array}$ \\
& \multicolumn{1}{c}{ Ya sabéis, } \\
& Boleno, que solo intento \\
Serviros, y yo seré & el que, así, de vos reciba \\
& honra y merced excesiva.
\end{tabular}

Tampoco aparece en escena el adjetivo ilustrísimo, que el propio Calderón emplea varias veces en su correspondencia formal (en la Carta a don Alonso Pérez de Guzmán, capellán mayor de los reyes ${ }^{31}$ ); la presencia excepcional de ilustre se

26. Vuseñoría tiene una presencia muy escasa en el corde: se limita casi por completo al siglo XVII, y en concreto a las obras dramáticas. Más del $80 \%$ de los testimonios se encuentra en El perro del hortelano de Lope de Vega, obra en la que la cuestión de las barreras sociales adquiere una relevancia especial. 27. Teatro cómico breve, vv. 122-124; p. 346.

28. La comicidad de Franchota reside en el lenguaje que Calderón crea para ella; es habitual que el entremés ofrezca un campo inmenso para todo tipo de experimentación lingüística. Remito a Arellano, 1995, pp. 662-668, para una descripción de los entremeses de Calderón de la Barca.

29. Haverkate 1994, pp. 162-172 explica que la oración imperativa no excluye una interpretación cortés, y expone los rasgos que condicionan esta interpretación.

30. La cisma de Ingalaterra, vv. 273-278 y 295-299; pp. 134-135. Hay más de doscientos testimonios de monsiur en el CORDE, que alcanzan hasta el siglo XIX; se encuentra en la producción literaria en el Siglo de Oro, pero especialmente en obras de contenido histórico y social. A la pronunciación se refiere Correas (Arte, p. 212): «en Aragon a los clérigos preponen Mosen semexante en algo a Monsieur de los Franzeses nobles que nosotros pronunziamos Monsiur ó Mosiur». El Diccionario de Autoridades la incluye como voz francesa que se usa en castellano hablando de los franceses (Aut., s.v.).

31. «llustrísimo señor: Mandóme vueseñoría Ilustrísima que, por que no pierda tiempo, me dé por advertido (...) no puede haber felicidad mayor que obedecer a Vueseñoría Ilustrísima» (Carta a don Alonso Pérez 
limita a las palabras que el Rey Basilio dirige a la corte de Polonia, en La vida es sueño (vv. 600-606; p. 148):

BASILIO sabéis (estadme atentos,
amados sobrinos míos,
corte ilustre de Polonia,
vasallos, deudos y amigos),
ya sabéis que yo en el mundo
por mi ciencia he merecido
el sobrenombre de docto.

A falta de personas ilustres y de señorías, el recurso que más abunda en las obras en las relaciones con el poder es el sustantivo señor, habitualmente construido como vocativo. Señor (o señora) es señal inequívoca de reverencia y respeto de inferior a superior, como indica Correas ${ }^{32}$, y se aplica a reyes e hijos de reyes, miembros de la nobleza y altos cargos del clero y del ejército. Como otros tratamientos, es compatible con el tuteo si existe familiaridad entre los interlocutores, y con el voseo si la relación es distante o el emisor quiere expresar respeto. Señor es el príncipe Federico para su criado Roberto (El alcaide de símismo, p. 802):

Estás, señor, herido;

Segismundo para Clotaldo (La vida es sueño, vv. 2402-2403; p. 233):

pues, señor, si el obrar bien

es ya tu blasón;

don Manuel para Cosme (La dama duende, vv. 925-926; p. 43) -y en todos ellos existe proximidad vivencial-:

Si tienes por inquilino,

señor, en tu casa un duende.

Y señor es el viejo y noble Tomás Boleno para Pasquín (La cisma de Ingalaterra, vv. 1697-1968; p. 195):

Tened paciencia, señor Tomás Boleno;

y el capitán para el príncipe Federico, en la escena disfrazado de villano (El alcaide de sí mismo, p. 820), en estos últimos con el pronombre vos o la forma verbal en plural:

Si vos, señor, me buscáis...

de Guzmán, 1652). Consultado en el CORDE.

32. «Tanbien por rreverenzia i rrespecto ponemos antes de todo señor» (Correas, Arte, p. 211). 
Compatible igualmente con proximidad y distancia, señora es la infanta Margarita para Serafina (El alcaide de sí mismo, p. 816):

$$
\begin{aligned}
& \text { Mi amor, señora, de quien } \\
& \text { tanta confianza tienes, } \\
& \text { te estima favor tan grande; }
\end{aligned}
$$

Rosaura para Clarín (La vida es sueño, vv. 45-46; p. 111):

Mas, ¿qué haremos, señora,

a pie, solos, perdidos y a esta hora...?;

y Rosimunda para Casimiro (El conde Lucanor, p. 1005):

Dadme, señora, a besar vuestra mano.

También combinado con el tuteo de confianza, gran señor está reservado para miembros de la realeza. El rey Basilio recibe este vocativo del viejo Clotaldo (La vida es sueño, v. 889; p. 159):

¡Vivas, gran señor, mil siglos!;

el rey moro de Muley (El príncipe constante, v. 139; p. 312):

Dame, gran señor, los pies;

y el príncipe Fernando del conde don Juan (El príncipe constante, vv. 914-916; p. 355):

$$
\begin{aligned}
& \text { Primero, gran señor, mi pecho fuerte, } \\
& \text { que es muro de diamante, } \\
& \text { tu vida guardará puesto delante. }
\end{aligned}
$$

En contraste con lo expuesto hasta aquí, no puede extrañar la generosidad de Calderón -como poeta de Corte- en el uso de apelativos honoríficos para reyes, príncipes o infantes en sus obras: el uso recurrente de majestad y alteza coincide con la participación habitual de representantes de la realeza en las piezas teatrales. Eso sí, la reverencia -verbal y gestual - tampoco excluye la familiaridad, como se ha visto hasta aquí; al contrario, y tal vez por el afán didáctico de Calderón (maestro de príncipes, según se ha dicho ${ }^{33}$ ), en la relación verbal con los representantes de la 
realeza de los dramas calderonianos conviven a menudo poder y solidaridad 34: así, majestad y alteza son compatibles con el voseo de la distancia, pero también con el tuteo de la proximidad vivencial y de la confianza.

Vuestra Majestad se reserva a reyes y reinas, de acuerdo con las indicaciones del protocolo. Es el trato que dispensa el príncipe de Sicilia al rey de Nápoles en su carta (El alcaide de sí mismo, p. 811):

REY DE SICILIA

Porque vuestra Majestad no esté con el cuidado que le puede dar mi ausencia, escribo con Roberto [...] volveré a los pies de vuestra Majestad, cuya vida el cielo aumente;

Ana Bolena a la reina Catalina (La cisma de Ingalaterra, vv. 493-496, p. 145):

$$
\begin{array}{ll}
\text { ANA BOLENA } & \text { Si favor tan soberano } \\
& \text { hoy merece mi humildad, } \\
& \text { deme Vuestra Majestad } \\
& \text { a besar su blanca mano; }
\end{array}
$$

o Clotaldo al rey Basilio (La vida es sueño, vv. 2048-2049; p. 216):

CLOTALDO

Señor, ¿así

Viene vuestra Majestad?

El sintagma exige la concordancia de verbo y posesivos en $3^{\circ}$ persona, pero, salvada la exigencia gramatical en la oración de la que participa, se puede producir el tránsito inmediato al tuteo (o del tuteo a la fórmula de reverencia), cuando existe un vínculo familiar, como entre Fénix y el rey Muley, su padre (El príncipe constante, vv. 1992-1995; pp. 411-412):

FÉNIX

$$
\begin{aligned}
& \text { Si ha merecido en tu amor } \\
& \text { gracia alguna mi humildad, } \\
& \text { hoy a Vuestra Majestad } \\
& \text { vengo a pedir un favor; }
\end{aligned}
$$

o cuando lo permite la cordialidad del intercambio, como ocurre en diálogo entre el capitán y el rey de Nápoles (El alcaide de sí mismo, p. 816) una vez formulado el saludo protocolario, ambos acceden al tuteo:

CAPITÁN

Deme

$$
\text { vuestra Majestad los pies. }
$$

exista en Calderón una actitud de servilismo propagandístico hacia el rey, e interpreta un sentido didáctico; el autor fundamenta su propuesta en algunas obras escritas para ser representadas en palacio. 34. Moreno Fernández, 2015, pp. 149-157. Con el término poder se hace referencia, en sociolingüística, a situaciones de distancia social entre dos interlocutores; supone una relación no recíproca, que se basa en diferentes parámetros (edad, riqueza, posición social, fuerza...). La solidaridad implica simetría en el tratamiento, y puede darse incluso en situaciones de poder. 
REY

CAPITÁN
¿Qué hay de nuevo?

Que sucede

a medida del deseo

tu pretensión.

El uso de la corte impone formas no verbales de adulación o sumisión - besar las manos o los pies, entre otras- que se emplean con frecuencia en el teatro, a juzgar por la presencia habitual de las expresiones que verbalizan este tipo de reverencias ${ }^{35}$.

En cuanto a su majestad, se encuentra solo cuando el rey no es interlocutor. Don Manuel, en La dama duende (vv. 83-85; p. 7) habla de este modo del rey, que no está presente:

\author{
Viendo que Su Majestad \\ con este gobierno premia \\ mis servicios ...
}

Tu majestad se limita a intercambios entre iguales. Lo utiliza Estela, protagonista de Amor, honor y poder, para dirigirse al rey Eduardo III. En la escena se muestra el tránsito de la desigualdad social a la proximidad vivencial: el rey le toma la mano, Estela accede al tuteo y a la fórmula tu majestad ${ }^{36}$ (Amor honor y poder, pp. 921922):

$\begin{array}{ll}\text { ESTELA } & \begin{array}{l}\text { Si Vuestra Majestad verme quería, } \\ \text { ¿por qué más descubierto no venía? [...] }\end{array} \\ \text { REY } & \begin{array}{l}\text { Tu gusto sólo es (iqué blanca mano!), } \\ \text { Estela, el que deseo [...] }\end{array} \\ \text { ESTELA } & \text { ¡Suelta, suelta la mano, } \\ & \text { que viene, jay de mí, triste!, allí mi hermano. } \\ & \text { Tu majestad se esconda. }\end{array}$

35. Guevara les dedica un extenso comentario en sus Epístolas familiares: «El estilo de la Corte es decirse unos a otros "beso las manos de vuestra merced", otros dicen "beso los pies a vuestra Señoría", otros dicen "yo soy siervo y esclavo perpetuo de vuestra casa". Lo que en este caso siento es que debía ser el que esto inventó algún hombre vano y liviano, y aun mal cortesano; porque decir uno que besará las manos a otro es mucha torpedad, y decir que le besa los pies es gran suçiedad. Yo vergüença he de oír decir "bésoos las manos", y muy grande asco he de oír decir "bésoos los pies", porque con las manos limpiámonos las narices, con las manos nos limpiamos la lagaña, con la mano nos rascamos la sarna y aun nos servimos con ellas de otra cosa que no es para decir en la plaça. Cuanto a los pies, no podemos negar sino que por la mayor parte andan sudados, traen largas las uñas, están llenos de callos y andan acompañados de adrianes y aun cubiertos de polvo o cargados de lodo» (Guevara, Epístolas, II, pp. 51-52. Consultado en el CORDE).

36. Estela representa el honor en esta primera comedia de Calderón, y es capaz de vencer al poder, según manifiesta el mismo rey al finalizar la obra: «Que una mujer ha sido/ tan noble/ que el poder haya vencido.» 
Emplea también tu majestad la reina Catalina, cuando se dirige a su esposo el rey Enrique VIII (La cisma de Ingalaterra, vv. 1074-1075; p. 170):

$$
\begin{aligned}
& \text { ¿Qué es lo que habla } \\
& \text { tu majestad con Volseo? }
\end{aligned}
$$

El sustantivo alteza, de acuerdo con las normas establecidas, se aplica a príncipes e infantes, y abunda también en las obras seleccionadas. De vuestra alteza trata Leonelo (criado) a Elena, hermana de príncipe (El alcaide de sí mismo, p. 807):

$$
\begin{aligned}
& \text { LEONELO Los villanos de Belflor, } \\
& \text { sabiendo que vuestra Alteza } \\
& \text { viene con tanta tristeza, } \\
& \text { para mostrar el amor [...] } \\
& \text { a besar sus plantas vienen. }
\end{aligned}
$$

Segismundo, que acaba de despertar en palacio como príncipe, recibe este apelativo de Clotaldo (además del vocativo gran señor); el respeto y la obediencia, inusitados hasta ese momento, le causan sorpresa (La vida es sueño, vv. 1260-1266; p. 178):

$$
\begin{array}{ll}
\text { CLOTALDO } & \text { Vuestra Alteza, gran señor, } \\
& \text { me dé su mano a besar; } \\
& \text { que el primero le ha de dar } \\
& \text { esta obediencia mi honor. } \\
\text { SEGISMUNDO } & \text { (Aparte). Clotaldo es; pues, ¿cómo así } \\
& \text { quien en prisión me maltrata } \\
& \text { con tal respeto me trata? }
\end{array}
$$

El tratamiento de alteza es compatible con los posesivos vuestra o tu, aunque este último es poco frecuente. La infanta Flérida recibe ambas formas de Teobaldo en un mismo diálogo, dependiendo de la modalidad del enunciado en que se insertan (exhortación vs. enunciación) (Amor, honor y poder, pp. 921-922). En todos los casos la concordancia se establece en $3^{\mathrm{a}}$ persona:

$\begin{array}{ll}\text { TEOBALDO } & \text { No salga vuestra Alteza, } \\ & \text { que un bárbaro accidente } \\ & \text { descortés no consiente } \\ & \text { respeto a la belleza [...] } \\ & \text { porque tu Alteza pueda } \\ \text { descansar, aquí queda } & \text { el Rey aquesta noche. }\end{array}$

Comentario aparte merece el caso de El príncipe constante, por la reflexión que ofrece este drama, directa o indirectamente, acerca del rango y del respeto que merece un príncipe convertido en esclavo, que en ocasiones contrasta con lo que revelan las fórmulas y formas de tratamiento. Así, mientras el príncipe declara que 
la esclavitud lo priva del rango y del trato que le corresponde por su origen (El príncipe constante, vv. 1367-1373; p. 379):

FERNANDO ¿Quién soy yo? ¿Soy más que un hombre?
$\begin{aligned} & \text { Si es número que acrecienta } \\ & \text { el ser Infante, ya soy } \\ & \text { un cautivo, de nobleza } \\ & \text { no es capaz el que es esclavo; } \\ & \text { yo lo soy, luego ya yerra } \\ & \text { el que infante me llamare; }\end{aligned}$

los cautivos con los que comparte prisión contradicen con sus palabras esta afirmación (El príncipe constante, vv. 1572-1575; pp. 389-390):

$\begin{array}{ll}\text { CAUTIVO2 Danos, señor, tus pies. } & \\ \text { FERNANDO } & \text { Alzad, amigo, } \\ & \text { no hagáis tal ceremonia ya conmigo, } \\ & \text { ved que humilde vivo, } \\ \text { que soy entre vosotros un cautivo. }\end{array}$

La condena definitiva del príncipe constante significa la pérdida del tratamiento de alteza que le dispensa el rey moro; sin embargo, entre Fernando y el rey se mantiene siempre la relación verbal de tuteo, que en este caso no puede significar proximidad vivencial, sino más bien igualdad jerárquica (El príncipe constante, vv. 2302-2316; p. 425) 37:

\begin{tabular}{ll} 
REY & \multicolumn{1}{c}{ Constante } \\
& te muestras a mi pesar. \\
& ¿Es humildad o valor \\
& Esta obediencia? \\
FERNANDO & \multicolumn{1}{c}{ Es mostrar } \\
& cuánto debe respetar \\
el esclavo a su señor; & y pues que tu esclavo soy \\
& y estoy en presencia tuya, \\
& esta vez tengo de hablarte, \\
& mi rey y señor, escucha: \\
& Rey te llamé y, aunque seas \\
& de otra ley, es tan augusta \\
& de los reyes la deidad, \\
& tan fuerte y tan absoluta, \\
& que engendra ánimo piadoso.
\end{tabular}

37. En el desenlace de la obra, el rey Alfonso de Portugal recibe el cadáver de Fernando como príncipe, y ya también mártir: «En mis brazos os recibo, / divino Príncipe mártir» (El príncipe constante, vv. 27572758; p. 445). 
Ya se ha señalado la escasa presencia de vuestra merced en las obras dramáticas de Calderón, frente a lo que sucede en otros textos literarios y no literarios del mismo tiempo ${ }^{38}$. En realidad, Calderón no precisa de este tratamiento (que estaba ya extendido para el trato distante y respetuoso ${ }^{39}$, porque distancia y proximidad se manifiestan en sus obras con vos y tút ${ }^{4}$. Tampoco cabe descartar que el autor trate de evitar una fórmula que incluye un sustantivo (merced o mercedes) cuyo empleo en uso libre es habitual, y que, por tanto, podría dar lugar a confusiones. Sea cual sea el motivo, lo cierto es que el sintagma vuestra merced y los distintos alomorfos surgidos a partir de él y vigentes en su tiempo sirven como recurso excepcional, y como tal adquieren valores singulares ${ }^{47}$.

Pese a la indicación de Correas (la gente vulgar y de aldea no tiene uso de hablar con merced), los escasos testimonios que he hallado en las obras seleccionadas ocurren, precisamente, en boca de criados y villanos ${ }^{42}$.

El villano Benito se dirige al príncipe Federico, que aparece desnudo, de vuesa merced. Benito, que aporta comicidad en todas las escenas en las que interviene, elige esta fórmula para recriminar al príncipe su descortesía (El alcaide de sí mismo, p. 807):

BENITO Señor desnudo, ¿hasta cuándo vuesa merced piensa habrar?

¿No pudo considerar

Que también yo estaba habrando?

Cosme, criado, emplea excepcionalmente la variante vuesarced, considerada rústica, para formular un ruego a don Luis (La dama duende, vv. 134-137; p. 9):

COSME Señor, aunque con vergüenza

llego, vuesarced me haga

38. Engelbert, 1973, p. 194.

39. Ver Martínez Gavilán, 1988: pp. 94-96, para otras consideraciones sobre el significado del tratamiento vuestra merced y formas derivadas en el siglo XVII; además, Rogers, 1924, pp. 118-120 para vuestra merced en la Novelas Ejemplares; Del Barrio, 1997, pp. 357-362 en El Quijote, y Medina Morales, 2002, pp. 1336-1337, en la novela picaresca. Remito a Fontanella, 1999, pp. 1411-1414, y Pérez-Salazar, 2002, pp. 882-887, sobre el uso de vuesa merced en la correspondencia privada entre familiares y en las relaciones amorosas en el siglo XVII respectivamente.

40. Girón, 2004, p. 863, explica que vos había entrado en colisión con vuestra merced a comienzos del siglo XVI, y que necesita el refuerzo de señor para seguir funcionando como fórmula deferente. Sin embargo, afirma Lapesa, 2000, p. 324, que damas y caballeros se tratan aún de vos en las comedias urbanas de Calderón, y que este uso se prolonga todavía en la comedia neoclásica.

41. Torres, 1989, pp. 320-331, presenta las numerosas formas que emplea Calderón en el teatro y los significados que adquieren en sus obras dramáticas.

42. Torres, 1989, pp. 320-331. Torres observa la diferencia entre el sintagma vuestra merced, que Calderón pone en boca de personajes de cualquier condición, y los distintos alomorfos que resultan a partir de la univerbación, que empelan solo los personajes de clases inferiores. La autora describe los valores específicos que esta forma de tratamiento adquiere en las obras de Calderón (invocaciones al público, muestra de desdén, manifestación de celos) y destaca su uso habitual como recurso para la comicidad. 
tan gran merced que me lea a quién esta carta dice.

Otra variante vulgar, ucé, es la forma que escoge el soldado Rebolledo para hablar al capitán (El alcalde de Zalamea, vv. 658-664; p. 271), y lo hace excepcionalmente, cuando este se enfada y suspende el tuteo. Nótese que el capitán opta por la tercera persona, sin tratamiento explícito, y Rebolledo se enfada también:

$\begin{array}{ll}\text { CAPITÁN } & \text { Pues ¿cómo me habla a mí de esa manera? } \\ \text { REBOLLEDO } & \begin{array}{l}\text { ¿No tengo de enojarme } \\ \text { cuando tengo razón? }\end{array} \\ \text { CAPITÁN } & \begin{array}{l}\text { No, ni ha de hablarme. } \\ \text { Y agradezca que sufro aqueste exceso. }\end{array} \\ \text { REBOLLEDO } & \begin{array}{l}\text { Ucé es mi capitán; solo por eso } \\ \text { callaré; mas, por Dios, que si yo hubiera } \\ \text { la bengala en mi mano... }\end{array}\end{array}$

Otros testimonios de distintas variantes formales aparecen en situaciones cómicas, entre graciosos en las comedias y personajes de entremés, o en boca de los representantes más bajos de la sociedad. Sirva como testimonio el diálogo entre La Chispa y Rebolledo, que encarnan, en El alcalde de Zalamea, «el mundo apicarado integrado en el ejército» ${ }^{43}$, y se intercambian vuecé, vusté y ucé (además de seor, cuyo propósito parece burlesco) (El alcalde de Zalamea, vv. 65-66 y 119-129; pp. 236 y 240):

$\begin{array}{ll}\text { CHISPA } & \text { Seor Rebolledo, por mí } \\ & \text { vuecé no se aflija, no; [...] } \\ \text { REBOLLEDO } & \text { ¿Es aquella Zalamea? } \\ \text { CHISPA } & \text { Dígalo su campanario. } \\ & \text { No sienta tanto vusté, } \\ & \text { que cese el cántico ya; } \\ & \text { mil ocasiones habrá } \\ & \text { en que logralle, porque } \\ & \text { esto me divierte tanto, } \\ & \text { que como de otras no ignoran } \\ & \text { que a cada cosica lloran, } \\ & \text { yo a cada cosica canto, } \\ & \text { y oirá ucé jácaras ciento. }\end{array}$

En cuanto a los entremeses, es en estas piezas donde más variantes introduce Calderón. Incluyo parte del diálogo entre María de Heredia y Nicolás (Entremés de 
la Premática, vv. 1-5 y 22-3344), en el que puede apreciarse la presencia de vusted, vuesarced y uced ${ }^{45}$ :

$\begin{array}{ll}\text { MARÍA } & \text { ¿Quiere vusted dejarme? } \\ \text { ¿Quiere no perseguirme ni cansarme? } & \text { ¿Aqueste es cautiverio, señor mío? } \\ & \text { ¿Hame comprado acaso el albedrío? } \\ \text { ¿Es nuestro amor la vida perdurable? } & \\ \text { [...] } & \\ \text { Vuesarced es lindo mozo, } \\ \text { pero mi moza no es linda } \\ \text { y con el amor del alma } \\ \text { la más hambrienta se ahíta. } \\ \text { El lienzo desta pared } \\ \text { el casero me lo alquila; } \\ \text { aunque él es lienzo casero } \\ \text { no es bueno para camisas. } \\ \text { La cara del sastre veo } \\ \text { mal pagada cada día } \\ \text { y mal le daré recado } \\ \text { si uced el mío me quita; }\end{array}$

Comentario aparte merece la forma usté, que utiliza de modo excepcional Pedro Crespo, protagonista de El alcalde de Zalamea, para dirigirse al sargento (El alcalde de Zalamea, vv. 465-480; p. 262). El diálogo es su primer intercambio, y el comportamiento verbal es rutinario y distante, más que cortés. Hechas las preguntas iniciales (con usté, los pronombres y el verbo en $3^{\mathrm{a}}$ persona), Crespo pasa a la $2^{\mathrm{a}}$ persona del plural, es decir, al voseo respetuoso, y se refiere al capitán, ausente, como su merced.

$\begin{array}{ll}\text { SARGENTO } & \text { ¿Vive Pedro Crespo aquí? } \\ \text { CRESPO } & \text { ¿Hay algo que usté le mande? } \\ & \text { Traer a su casa la ropa } \\ & \text { de don Álvaro de Ataide } \\ \text { CRESPO } & {[. . .]} \\ & \text { No digáis más; esto baste. } \\ & \text { Que para servir al rey, } \\ & \text { y al rey en sus capitanes, } \\ & \text { están mi casa y mi hacienda. } \\ & \text { Y en tanto que se le hace } \\ & \text { el aposento, dejad } \\ & \text { la ropa en aquella parte } \\ & \text { y id a decirle que venga, }\end{array}$

44. $1^{\text {a }}$ parte. Teatro cómico breve, pp. 9-10.

45. Otras formas en Entremés de la premática. 2ª parte: «Nicolás. Oiga, usted, diréselo cantando»; «María. Oiga, escuche, espere, tenga / vuesamerced, no se vaya» (Teatro cómico breve, vv. 128 y 133, p. 55); y Don Pegote: «Paje. No los nombre vuested» (Teatro cómico breve, v. 48; p. 83). 
cuando su merced mandare, a que se sirva de todo.

El mismo Crespo elige siempre vos (u otras formas casuales más las formas verbales de plural), y el vocativo señor, para el trato respetuoso a las autoridades que intervienen en la obra (El alcalde de Zalamea, vv. 759-762 y 850-854, pp. 276 y 281); nótese que él recibe el mismo tratamiento pronominal y verbal:

\begin{tabular}{cl}
\multicolumn{1}{c}{ Detened, } \\
CRESPO & $\begin{array}{c}\text { señor capitán; que yo } \\
\text { puedo tratar a mi hijo } \\
\text { como quisiere, y vos no. }\end{array}$ \\
CRESPO & $\begin{array}{l}\text { Mil gracias, señor, os doy } \\
\text { por la merced que me hicisteis, } \\
\text { de excusarme una ocasión } \\
\text { de perderme. }\end{array}$ \\
DON LOPE & ¿Cómo habíais, \\
& decid, de perderos vos?
\end{tabular}

El hecho de que quien emplea usté sea precisamente Pedro Crespo, villano, pero rico y alcalde, y que se presenta en la obra como hombre modélico ${ }^{46}$, invita, según creo, a reflexionar sobre la extensión social de esta variante (usted o usté) en su tiempo, que posiblemente fuera rústica, pero quizá de consideración menos vulgar que otros alomorfos: Calderón, conocedor de los usos lingüísticos de su tiempo, no puede escoger para Crespo cualquier variante, sino la menos proscrita o la única no proscrita ${ }^{47}$.

\section{FINAL}

Soy consciente de que esta aportación, basada en un grupo reducido de obras, no puede agotar todo lo relativo a la interpretación de las formas de tratamiento en el teatro de Calderón. Será necesario ampliar el análisis con el examen de otras piezas del autor - que merece un estudio tan completo como el que ya ha recibido Lope de Vega ${ }^{48}$-; incluso cabría decir que cada una de las obras analizadas podría recibir un estudio independiente de las formas y fórmulas de tratamiento. Así pues, cualquier conclusión que presente aquí ha de ser forzosamente parcial.

46. Como indica Escudero, editor de la obra, el conflicto social adquiere especial protagonismo, ya que se enfrenta al campesino modélico y justo con el militar de comportamiento vil, y se «conduce a una reflexión honda sobre la justicia, su papel y su aplicación en una sociedad desigual» (El alcalde de Zalamea, p. 62)

47. Para Martínez Gavilán, 1988, p. 98, «en los últimos años del siglo XVII ya se había producido [...] el proceso de extensión y difusión de la variante usted, que, considerada originariamente vulgar, pasó a convertirse en la forma usual para el trato respetuoso general». De la misma opinión es Sáez Rivera, 2006, pp. 2907-2908, que cuestiona la afirmación de Lapesa sobre la propagación de la variante usted, que, entiende Sáez, debió de generalizarse entre el pueblo por un deseo de imitación de la clase noble. 48. Ly, 1981. 
En su trabajo sobre la interlocución en el teatro calderoniano, Carrasco (1983, pp. 1098-1099) recordaba las restricciones que imponía en los autores clásicos la norma del decoro, arraigada en la conciencia artística. Sin embargo, recuerda, «el carácter piramidal de la sociedad barroca no se pone en peligro por el evidente distanciamiento entre los sistemas de la sociedad y de la escena». Así, frente al sistema sociolingüístico de su tiempo, complejo y en tránsito, Calderón adopta un sistema sociodramático, más sencillo y más estable, en el que la vigencia de vos se prolonga hasta el último tercio del siglo XVII para la indicación de respeto, y vuestra merced (y alomorfos) adquieren significados excepcionales.

El análisis de los elementos reservados a los representantes del poder permite hablar de simplificación de las rigurosas reglas sociolingüísticas. Pese a que conoce las pautas que imponen las normas, Calderón prescinde de la mayor parte de los apelativos, y se sirve de modo recurrente de los destinados a los representantes de la realeza (majestad y alteza), además de señor, y solo excepcionalmente de otras fórmulas. En todos los casos, aunque se respeta la concordancia gramatical en $3^{a}$ persona, las fórmulas coexisten con tuteo y voseo de acuerdo con la cortesía que impone el intercambio y con la proximidad o distancia vivencial que el autor quiere mostrar entre los interlocutores. De este modo, la reverencia (combinada con el lenguaje gestual, presente también en fórmulas verbales estereotipadas) es compatible con el poder y con la solidaridad.

Las formas de tratamiento a la autoridad en el drama calderoniano constituyen un recurso orientado a distintos fines: además de su significado intrínseco en la escena, indicador de cortesía o descortesía, confianza o distancia, respeto o desprecio, contribuyen a la caracterización de los personajes y a la consideración que puedan merecer por parte del público.

\section{BIBLIOGRAFÍA}

Arellano, Ignacio, Historia del teatro español del siglo XVII, Madrid, Cátedra, 1995.

Arellano, Ignacio, «"Decid al rey cuanto yerra". Algunos modelos de mal rey en Calderón», en El teatro clásico español a través de sus monarcas, ed. Luciano García Lorenzo, Madrid, Fundamentos, 2006, pp. 149-180.

Alvar, Manuel y Bernard Pottier, Morfología histórica del español, Madrid, Gredos, 1987, $1^{\text {a }}$ reimpresión de la $1^{\text {a }}$ ed.

Blas Arroyo, José Luis, «Los pronombres de tratamiento y la cortesía», Revista de Filología de la Universidad de La Laguna, 13, 1994, pp. 7-35.

Brown, Roger y Albert Gilman, "The pronouns of Power and Solidarity», en Style in Language, ed. Thomas A. Sebeok, Cambridge, MIT Press, 1960, pp. 253-276.

Calderón de la Barca, Pedro, Amor, honor y poder, en Comedias, II, Madrid, Fundación José Antonio de Castro, 2007, pp. 905-988. 
Calderón de la Barca, Pedro, El alcaide de sí mismo, en Obras completas, ed. Ángel Valbuena Prat. Madrid, Aguilar, 1956, pp. 802-832.

Calderón de la Barca, Pedro, El alcalde de Zalamea, edición crítica de las dos versiones de Juan Manuel Escudero Baztán, Madrid/Frankfurt, Iberoamericana/ Vervuert, 1998.

Calderón de la Barca, Pedro, El conde Lucanor, en Comedias, IV, Madrid, Fundación José Antonio de Castro, 2010, pp. 919-1038.

Calderón de la Barca, Pedro, El príncipe constante, ed. Joseba Cuñado Landa, Kassel, Reichenberger, 2014.

Calderón de la Barca, Pedro, El santo rey don Fernando (segunda parte), ed. Carmen Pinillos, Pamplona/Kassel, Universidad de Navarra/Reichemberger, 2016.

Calderón de la Barca, Pedro, La cisma de Ingalaterra, ed. Juan Manuel Escudero Baztán, Kassel, Reichenberger, 2001.

Calderón de la Barca, Pedro, La dama duende, ed. Fausta Antonucci, estudio preliminar Marc Vitse, Barcelona, Crítica, 1999.

Calderón de la Barca, Pedro, La vida es sueño (Comedia, auto y loa), ed. Enrique Rull, Madrid, Alhambra, 1980.

Calderón de la Barca, Pedro, Teatro cómico breve, ed. María Luisa Lobato, Kassel, Reichenberger, 1989.

Carrasco, Félix, «La interlocución en el teatro calderoniano: manipulación dramática de la práctica sociolingüística», en Calderón. Actas del Congreso internacional sobre Calderón y el teatro español del Siglo de Oro, ed. Luciano García Lorenzo, Madrid, CSIC, 1983, pp. 1091-1099.

Coenen, Erik, «Calderón, educador de príncipes», en Emocionar escribiendo. Teatralidad y géneros literarios en la España áurea, ed. Luciana Gentilli y Renata Londero, Madrid/Frankfurt, Iberoamericana/Vervuert, 2011, pp. 147-157.

Correas, Gonzalo, Arte de la lengua española castellana (Arte) [1635], ed. Emilio Alarcos García, Madrid, Anejo LVI de la Revista de Filología Española, 1954.

Covarrubias, Sebastián de, Tesoro de la lengua castellana o española (Cov.), ed. Ignacio Arellano y Rafael Zafra, Pamplona/Madrid/Frankfurt, Universidad de Navarra/Iberoamericana/Vervuert, 2006.

Cruickshank, Don William, Calderón de la Barca: su carrera secular, trad. José Luis Aristu, Madrid, Gredos, 2011.

Del Barrio Estévez, Laura, «Vacilaciones en el sistema de tratamiento del español clásico: El Quijote, II Parte», Verba, 24, 1997, pp. 349-370.

Enguita, José María, «Fórmulas de tratamiento en El Criticón», en Gracián y su época. Actas de la I Reunión de Filólogos Aragoneses, Zaragoza, Institución Fernando el Católico, 1986, pp. 295-316. 
Fontanella de Weinberg, Beatriz, «Sistemas pronominales de tratamiento en el mundo hispánico», en Gramática descriptiva de la lengua española, ed. Ignacio Bosque y Violeta Demonte, Madrid, Espasa, 1999, pp. 1399-1425.

Girón Alconchel, José Luis, «Cambios gramaticales en los Siglos de Oro», en Historia de la lengua española, coord. Rafael Cano, Barcelona, Ariel, 2004, pp. 859893.

Gracián Dantisco, Lucas, El Galateo español [1593], ed. Margarita Morreale, Madrid, CSIC, 1968.

Guevara, Fray Antonio de, Epístolas familiares [1521-1543], Madrid, Real Academia Española, 1950-1952.

Haverkate, Henk, La cortesía verbal. Estudio pragmalingüístico, Madrid, Gredos, 1994.

Lapesa, Rafael, «Personas gramaticales y tratamientos en español», en Morfosintaxis histórica del español, ed. Rafael Cano y Ma. Teresa Echenique, 2000, vol. I, pp. 311-345 (antes en Revista de la Universidad de Madrid, XIX, Homenaje a Menéndez Pidal, IV, 1970, pp. 167-193).

Leyes. Tomo primero de las leyes de recopilación que contiene los libros primero, segundo, tercero, quarto i quinto, Libro quarto. Título primero, Lei XVI, Madrid, 1775, pp. 556-560. Disponible en: < https://books.google.es> [07/12/2017].

Ly, Nadine, La poétique de l'interlocution dans le théatre de Lope de Vega, Burdeos, Institut d'Études Ibèriques et Ibéroamericaines de I'Université de Bordeaux, 1981.

Martínez Gavilán, María Dolores, «Formas de tratamiento en el siglo XVII», Estudios humanísticos. Filología, 10, 1988, pp. 85-105.

Medina Morales, Francisca, «Las formas nominales de tratamiento en el Siglo de Oro. Aproximación sociolingüística», en Actas del VI Congreso Internacional de la AISO, ed. M. ${ }^{a}$ Lusia Lobato y Francisco Domínguez Matito, 2002, pp. 1329-1341.

Moliner, María, Diccionario de uso del español (DUE) [1900-1981], Madrid, Gredos, 1990.

Moreno, María Cristobalina, «La cortesía verbal en el Siglo de Oro: los actos de habla directivos. Un estudio de pragmática histórica», en Actas del V Congreso Internacional de Historia de la Lengua Española, ed. $\mathrm{M}^{\mathrm{a}}$. Teresa Echenique y Juan Sánchez Méndez, Madrid, Gredos, 2002, pp. 1347-1359.

Moreno Fernández, Francisco, Principios de sociolingüística y sociología del lenguaje, Barcelona, Ariel, 2015, 4ª ed.

Pérez-Salazar, Carmela, «Manifestaciones del habla coloquial en un tipo de escrito: las cartas de amor (siglos XVI-XVIII)», en Actas del V Congreso Internacional 
de Historia de la Lengua Española, ed. Ma ${ }^{a}$. Teresa Echenique y Juan Sánchez Méndez, Madrid, Gredos, 2002, pp. 876-890.

Pla Cárceles, José, «La evolución del tratamiento «vuestra merced», Revista de Filología Española, 10, 1923, pp. 245-280 y 402-403.

Real Academia Española (CORDE), Banco de datos [en línea], Corpus diacrónico del español. Disponible en: <www.rae.es> [25/11/2017].

Real Academia Española, Diccionario de Autoridades (Aut.), Madrid, Gredos, 2002, 3 vols.

Rogers, Paul Patrick, «The forms of address in the Novelas Ejemplares of Cervantes», The Romanic Review, 1924, pp. 105-120.

Sáez Rivera, Daniel M., «Vuestra merced > usted: nuevos datos y perspectivas», en Actas del VI Congreso Internacional de Historia de la Lengua Española, ed. José Jesús de Bustos Tovar y José Luis, Girón, Madrid, Arco/Libros, 2006, pp. 2899-2911.

Torres, Victoria B., «Vuestra merced y sus alomorfos en el teatro de Calderón», RIL$C E, 5,2,1989$, pp. 317-331. 
